\title{
AC Iron Loss Prediction and Magnetic Properties of Fe-6.5 wt. \% Si Ribbons Prepared by Melt-Spinning
}

\author{
Shuai Wang, Yongfeng Liang * (1), Biao Chen, Feng Ye and Junpin Lin \\ State Key Laboratory for Advanced Metals and Materials, University of Science and Technology Beijing, \\ Beijing 100083, China; wangshuaizrr@126.com (S.W.); chenbiaoustb@126.com (B.C.); \\ yefeng@skl.ustb.edu.cn (F.Y.); linjunpin@ustb.edu.cn (J.L.) \\ * Correspondence: liangyf@skl.ustb.edu.cn; Tel.: +86-10-8237-6643
}

Received: 8 March 2018; Accepted: 10 April 2018; Published: 11 April 2018

\begin{abstract}
Ultra-thin Fe-6.5 wt. \% Si ribbons of $35 \mu \mathrm{m}$ in thickness were prepared by melt-spinning. The magnetic properties were investigated before and after annealing at $1000^{\circ} \mathrm{C}$. The DC properties and low-frequency $(400 \mathrm{~Hz} 10 \mathrm{kHz})$ iron losses significantly improved after heat treatment. A simplified formula- $P_{t}=k_{t} B_{m}^{N}$-based on the Steinmetz law, which can be used to predict the AC iron loss, is presented. The symbols " $k_{t}$ " and " $N$ " are defined as functions of microstructure and frequency. According to the tested results of iron loss, the values of " $k_{t}$ " and " $N$ " can be fitted and therefore the simplified formula can be determined. The extent of AC iron losses can be predicted according to the formula. The results obtained from the formula predict AC iron loss to a good degree. The method developed in this work could be extended to other magnetic materials for predicting AC iron loss with greater ease.
\end{abstract}

Keywords: Fe-6.5 wt. \% Si; ribbon; melt-spinning; AC iron loss prediction; magnetic properties

\section{Introduction}

Silicon steels are mainly used in transformers, power generators, and motors as important soft magnetic materials. In these, core loss occurs due to hysteresis and eddy current circulation during usage, wherein the hysteresis loss is proportional to the frequency, and the eddy current loss is proportional to the square of the frequency. Therefore, eddy current loss accounts for a large proportion in high-frequency use.

Compared with ordinary silicon steel, Fe-6.5 wt. \% Si (high silicon steel) alloy has many advantages in terms of magnetic properties, such as its properties of near-zero magnetostriction, high permeability, high resistivity, and low core loss [1]. The high resistivity aids in the suppression of the eddy current and thus leads to a significant reduction in eddy current loss.

However, due to the brittleness of Fe- $6.5 \mathrm{wt}$. \% Si originated from ordered phases of B2 and $\mathrm{D0}_{3}[2,3]$, it is extremely difficult to produce the Fe- $6.5 \mathrm{wt}$. \% Si alloy by the traditional hot-cold rolling process. Rapid solidification can suppress the transformation of ordered phases due to the high cooling rate, and thereby enhance the ductility [4]. Melt-spinning can be used for refining grains [5] and preparing magnetic material ribbons with good magnetic properties [6]. Previously, high-silicon steel ribbons of $25 \mathrm{~mm}$ in width were prepared by melt-spinning [7]. In this paper, various heat treatments were applied to the as-spun Fe-6.5 wt. \% Si ribbons. The relationship between microstructures and magnetic properties was investigated. In addition, a method based on Steinmetz law for prediction of iron loss is presented and verified. 


\section{Materials and Methods}

Herein, Fe-6.5 wt. \% Si ribbons with $35 \mu \mathrm{m}$ thickness were used. The composition of the ribbons measured by chemical analysis was Fe: $93.54 \mathrm{wt}$ \%, Si: $6.46 \mathrm{wt}$. \%. Micromorphology and cross sections of the ribbons were observed using a Zeiss Supra 55 (Carl Zeiss AG, Oberkochen, Germany) scanning electron microscope (SEM).

For magnetic properties measurement, the Fe-6.5 wt. \% Si ribbons were cut into $10 \mathrm{~mm}$ widths and subsequently coated with $\mathrm{MgO}$ powder, which plays dual roles of insulation and adhesion prevention. Moreover, the ribbons were wound into a toroidal core of $32 \mathrm{~mm}$ inner and $40 \mathrm{~mm}$ outer diameter, respectively (Figure 1 inset). The alternating current (AC) and direct current (DC) magnetic properties were measured using NIM-2000S AC and NIM-3000S DC instruments (National Institute of Metrology, Beijing, China), respectively. $\mathrm{B}_{8}, \mathrm{~B}_{50}$ were tested at magnetic field strengths of $800 \mathrm{~A} / \mathrm{m}$ and $5000 \mathrm{~A} / \mathrm{m}$, respectively.

To explore the changes in magnetic properties with greater accuracy and reduce the number of errors caused by differences between the different samples, the same core was tested over five rounds of measurements. It should be noted that first the core was tested without heat treatment and subsequently it was annealed in an Ar atmosphere at $1000{ }^{\circ} \mathrm{C}$ for $0.5 \mathrm{~h}$ ), following which the magnetic properties were tested. Subsequently, the same core was heated in an Ar atmosphere at $1000{ }^{\circ} \mathrm{C}$ for $1 \mathrm{~h}$ (referred to as $1.5 \mathrm{~h}$ ), then at $1000^{\circ} \mathrm{C}$ for $1.5 \mathrm{~h}$ (referred to as $3 \mathrm{~h}$ ) and then another $2 \mathrm{~h}$ (referred to as $5 \mathrm{~h}$ ). After each heat treatment, the magnetic properties were tested and the grain sizes were observed.

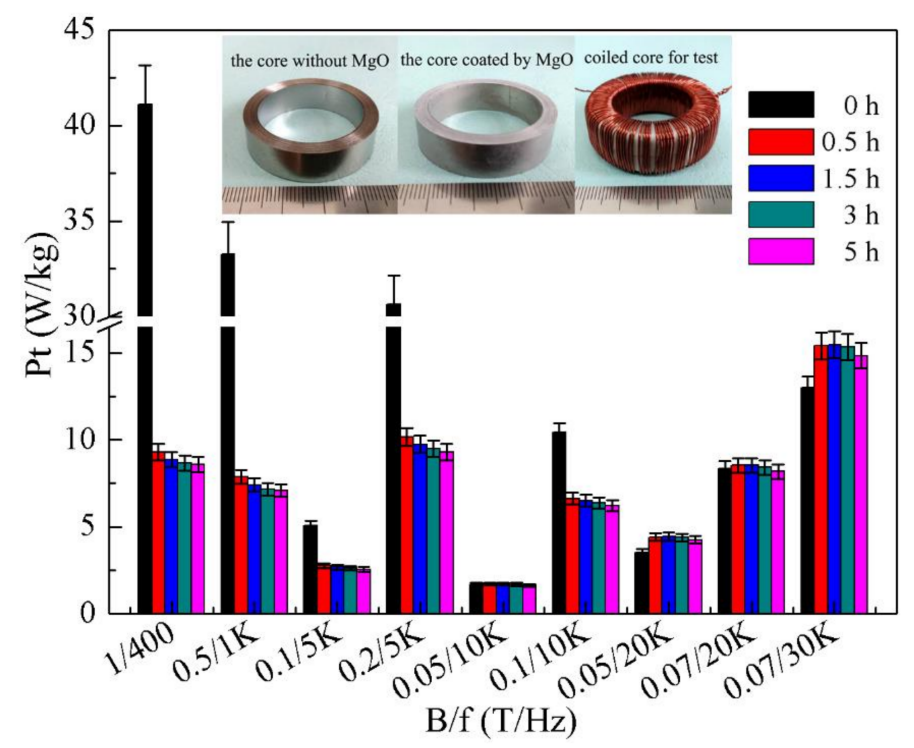

Figure 1. Iron losses corresponding to different conditions before after heat treatment; the inset represents the samples for test.

\section{Results and Discussion}

The DC properties of Fe-6.5 wt. \% Si ribbons are shown in Table 1, and it is evident that the DC properties greatly improved after the $1000{ }^{\circ} \mathrm{C}$ heat treatment, which is reflected in the improvement of the magnetic permeability, $\mathrm{B}_{8}$, and reduction in coercivity value. It is observed that there is almost no change in $\mathrm{B}_{50}$ before and after heat treatment, owing to the sufficiently large magnitude of the external magnetic field, resulting in the same value of the magnetic induction due to an identical arrangement of the magnetic domain.

Figure 1 presents the values of $\mathrm{AC}$ iron losses. The iron loss corresponding to the frequency range between $400 \mathrm{~Hz}$ and $10 \mathrm{kHz}$ shows a decreasing trend with heat treatment at $1000^{\circ} \mathrm{C}$. For frequencies higher than $10 \mathrm{kHz}$, the iron loss increases compared to the as-spun state. Figure 2a-e show the free 
surfaces of the ribbons and Figure $2 \mathrm{f}$ depicts the grain sizes on the free surface with respect to the annealing time. Figure 2a,b insets represent the longitudinal sections of the ribbons before and after heat treatment. The original ribbons consist of equiaxed grains on the wheel surface (the surface contacting the copper roller) and columnar grains on the free surface (the surface not contacting the roller). The grain size is small and uniform. After being subjected to $1000{ }^{\circ} \mathrm{C}$ for $0.5 \mathrm{~h}$, each grain extends through the entire thickness, and the grain size increases from a few microns to about 30 microns. With increasing heat treatment time, the grain size tends to increase, but very slowly. The ribbon surfaces would hinder the growth of grain size [8]. After heat treatment, the grain growth results in reduction of grain boundaries, which aids in the reduction of the obstacles of the movement of magnetic domains, thereby reducing the hysteresis loss.

Table 1. DC properties of Fe- 6.5 wt. \% Si ribbons.

\begin{tabular}{ccccc}
\hline \multirow{2}{*}{ Sample } & \multirow{2}{*}{$\mu_{\mathrm{m}}$} & \multicolumn{2}{c}{$\mathbf{B}(\mathbf{T})$} & \multirow{2}{*}{ Hc $(\mathbf{A} / \mathbf{m})$} \\
\cline { 3 - 4 } & & $\mathbf{B}_{\mathbf{8}}$ & $\mathbf{B}_{\mathbf{5 0}}$ & \\
\hline $0 \mathrm{~h}$ & $1843 \pm 60$ & $1.16 \pm 0.02$ & $1.55 \pm 0.03$ & $237.6 \pm 6.8$ \\
$0.5 \mathrm{~h}$ & $10,589 \pm 311$ & $1.31 \pm 0.03$ & $1.55 \pm 0.04$ & $48.9 \pm 1.6$ \\
$1.5 \mathrm{~h}$ & $10,931 \pm 327$ & $1.31 \pm 0.04$ & $1.55 \pm 0.03$ & $46.6 \pm 1.3$ \\
$3 \mathrm{~h}$ & $11,082 \pm 295$ & $1.31 \pm 0.03$ & $1.55 \pm 0.05$ & $45.7 \pm 1.0$ \\
$5 \mathrm{~h}$ & $11,051 \pm 301$ & $1.32 \pm 0.04$ & $1.56 \pm 0.04$ & $45.3 \pm 1.1$ \\
\hline
\end{tabular}
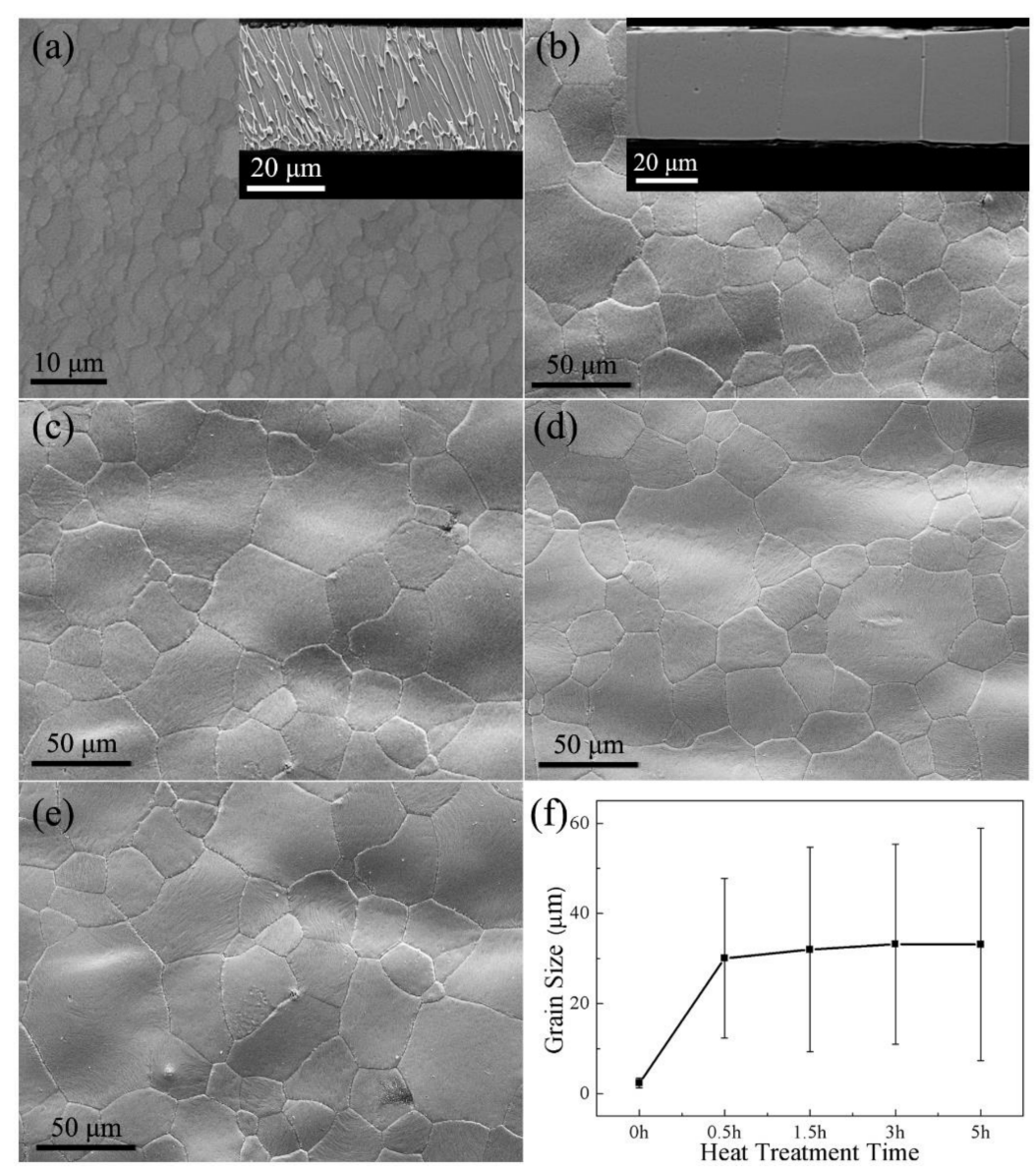

Figure 2. Free surface microstructure of Fe-6.5 wt. \% Si ribbons (a) in the absence of heat treatment; (b) $1000{ }^{\circ} \mathrm{C}, 0.5 \mathrm{~h}$; (c) $1000{ }^{\circ} \mathrm{C}, 1.5 \mathrm{~h}$; (d) $1000{ }^{\circ} \mathrm{C}, 3 \mathrm{~h}$; (e) $1000{ }^{\circ} \mathrm{C}, 5 \mathrm{~h}$. (f) Grain size statistics. 
Figure 3 depicts the results of the hysteresis loss curves and the AC iron loss curves. It is well known that the Steinmetz law [9] is used to describe the relationship between $P_{h y s}$ (hysteresis loss) and $B_{m}$ (maximum magnetic induction), wherein: $P_{h y s}=k_{h} B_{m}^{n}$ at DC field, where, $\mathrm{k}_{\mathrm{h}}$ is the hysteresis loss coefficient, and $\mathrm{n}$ is the exponent of $B_{m}$, which is always near 1.6. The different color formulas in the Figure 3a represent the fitting results of DC iron loss for different heat treatment time. $R^{2}$ is the goodness of fit and the closer the value is to 1, the better the fit is. From Figure 3a, the DC iron losses decrease drastically after heat treatment and tend to decrease with the extension of the duration of heat treatment, and the coefficients of the fitted results (" $k_{h}$ " values) also have such a tendency. Generally, the " $k_{h}$ " value is affected by the kind of material, thickness, stress, grain size, etc. Any factor that reduces the resistance of magnetic domain motion can reduce the " $k_{h}$ " value.
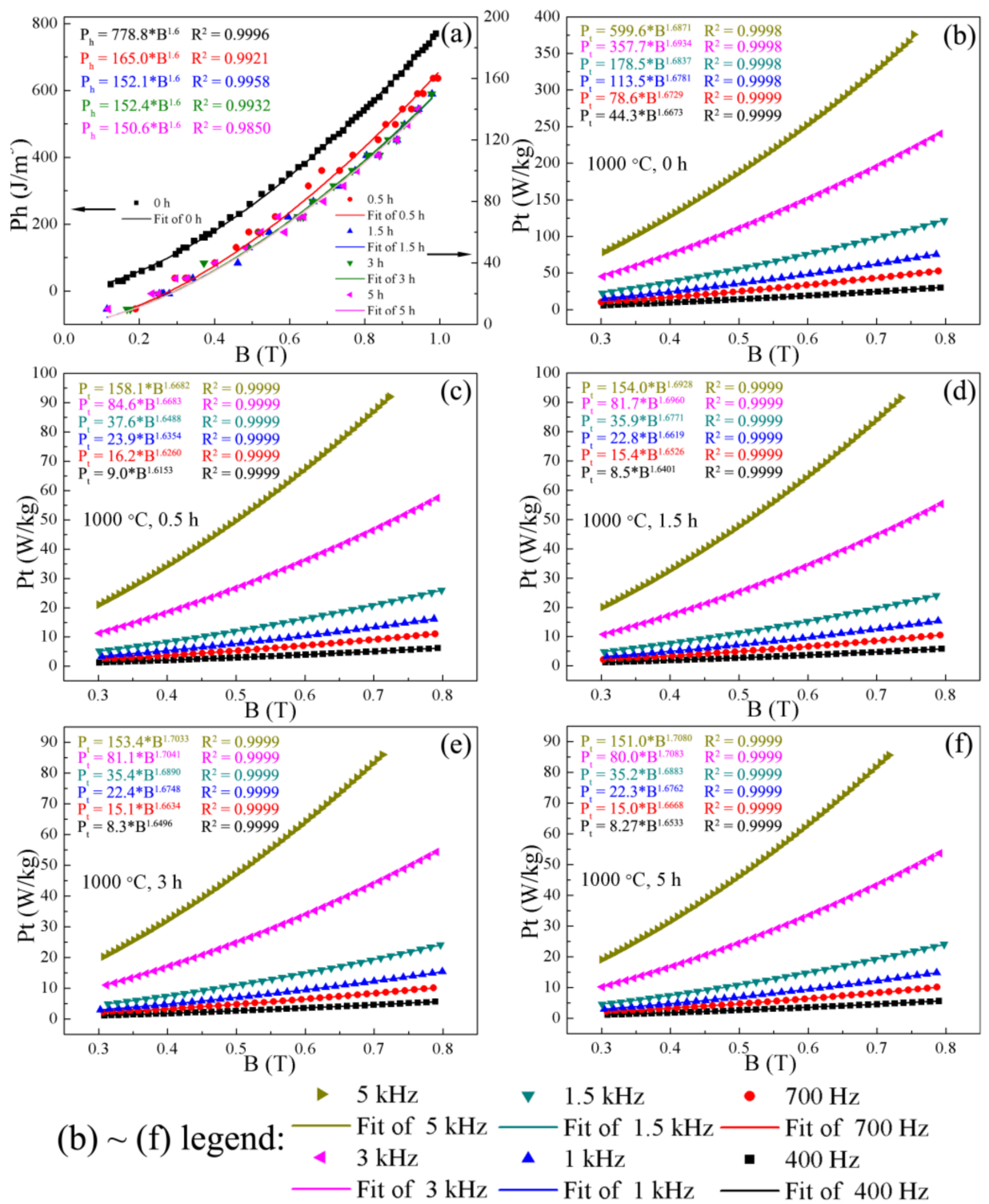

Figure 3. DC iron losses $\left(P_{h}\right)$ and AC iron losses $\left(P_{t}\right)$ and fit results before and after heat treatment, (a) DC iron losses-magnetic induction curves, which has two y axes: the left vertical axis represents DC iron losses $\left(P_{h}\right)$ before heat treatment and the right vertical axis represents DC iron losses $\left(P_{h}\right)$ after heat treatment with different duration; $(\mathbf{b}-\mathbf{f})$ AC iron losses-magnetic induction curves at different frequencies. $R^{2}$ is the goodness of fit wherein, the closer the value is to 1 , the better the fit is. 
Ever since Steinmetz formulated the law, many modifications have been proposed, such as the "AC Steinmetz law": $P_{t}=k_{a c} B_{m}^{n} f^{\alpha}$, where $P_{t}$ is the total iron loss under AC conditions, $k_{a c}$ is the loss coefficient, $\mathrm{n}$ is the exponent of maximum magnetic induction $B_{m}$ and $\alpha$ is the exponent of $\mathrm{AC}$ frequency $f[10,11]$. Upon comparing the hysteresis loss curve and the AC iron loss curve in Figure 3, it can be seen that their shapes are similar, exhibiting monotonically increasing concave functions. Here, we simplify the AC Steinmetz law into $P_{t}=k_{t} B_{m}^{N}$ similar to "Steinmetz law" $P_{h y s}=k_{h} B_{m}^{n}$ and different to "AC Steinmetz law" $P_{t}=k_{a c} B_{m}^{n} f^{\alpha}$ where, " $k_{t}$ " and " $N$ " are defined as functions of microstructure and frequency. According to the tested results of iron loss, the values of " $k_{t}$ " and " $N$ " can be fitted using the simplified formula $-P_{t}=k_{t} B_{m}^{N}$, as shown in Figure $3 \mathrm{~b}-\mathrm{f}$. The different color formulas represent the fitting results of different frequencies. The prediction of iron loss through the formula- $P_{t}=k_{t} B_{m}^{N}$ is based on determining of " $k_{t}$ " and " $N$ ".

Figure $4 \mathrm{a}, \mathrm{b}$ depict the results of " $k_{t}$ " and " $N$ ". The different color formulas represent the fitting results of " $k_{t}$ " and " $N$ " at different frequencies. Based on the fitting results, the values of " $k_{t}$ " and " $N$ " can be calculated at other frequencies. Then, " $k_{t}$ " and " $N$ " are taken into AC iron loss formula to predict the iron loss at other frequencies, such as $1.3 \mathrm{kHz}, 4 \mathrm{kHz}$. From the Figure $4 \mathrm{a}, \mathrm{b}$ fitting results, " $k_{t}$ " and " $N$ " can be gained at $1.3 \mathrm{kHz}, 4 \mathrm{kHz}$ and core losses prediction results are shown in the Figure $4 \mathrm{c}, \mathrm{d}$. In order to verify the accuracy of the prediction, iron losses were tested and compared at $1.3 \mathrm{kHz}$ and $4 \mathrm{kHz}$. From Figure $4 \mathrm{c}$,d, the calculated value was found to be in good agreement with the actual test results.
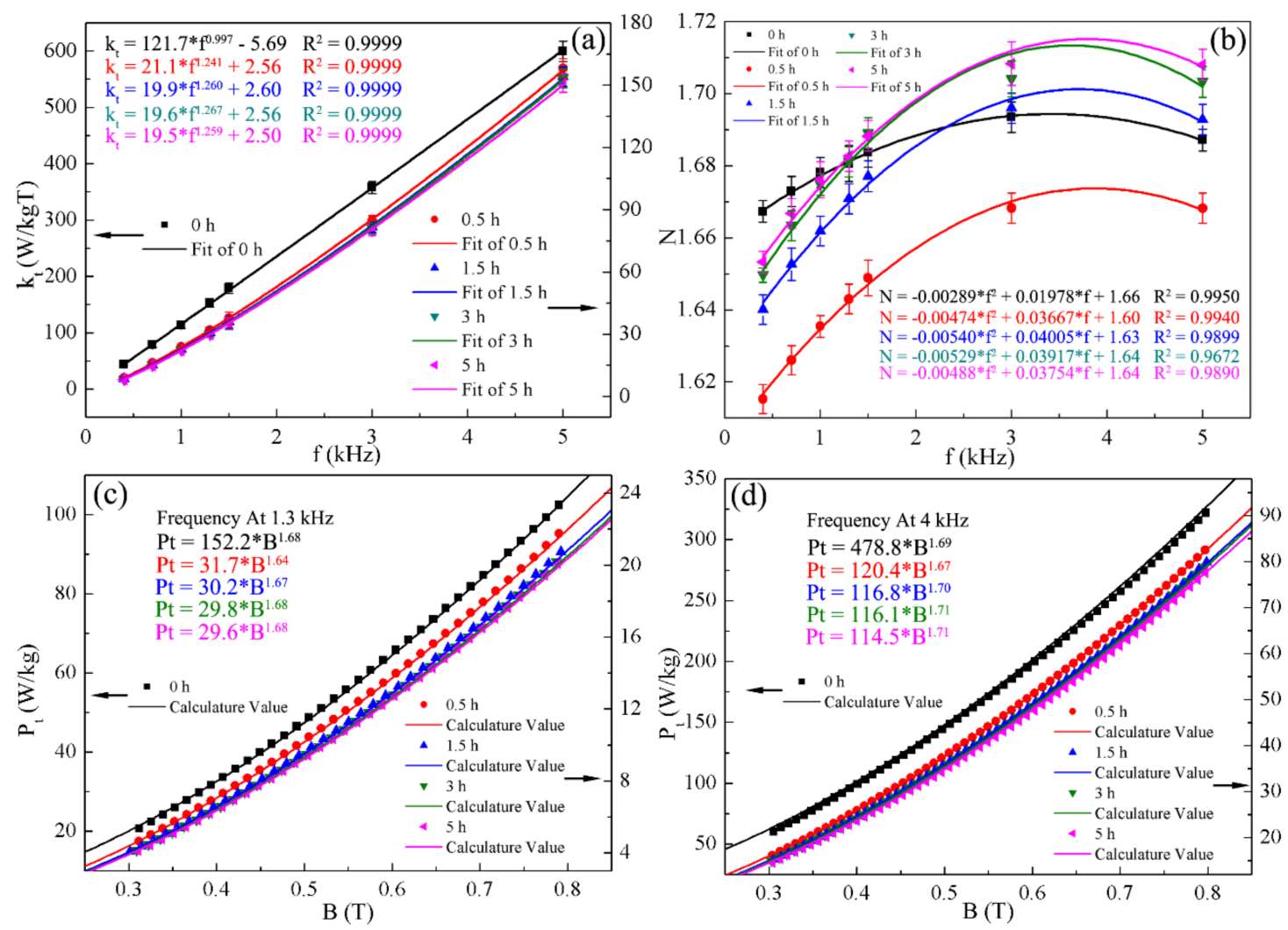

Figure 4. (a) AC iron loss coefficient $k_{t}$ and fit results; (b) AC iron loss factor $N$ and fit results. The iron loss test result and calculation value at (c) $1.3 \mathrm{kHz}$ frequency and (d) $4 \mathrm{kHz}$ frequency. (a,c,d) have two $\mathrm{y}$ axes: the left vertical axe represents results before heat treatment and the right vertical axe represents results after heat treatment with different duration.

In addition, the "AC Steinmetz law" $\left(P_{t}=k_{a c} B_{m}^{n} f^{\alpha}\right)$ shows the total iron loss is affected by magnetic induction intensity and frequency. If this formula is used to predict the AC iron losses, first the exponent " $n$ " value, " $\alpha$ " value and the coefficient " $k_{a c}$ " should be fitted out from iron loss-magnetic 
induction intensity curves at a certain frequency or from iron loss-frequency curves at a certain magnetic induction intensity. However, at other frequency or magnetic induction intensity, the value of " $n$ " and " $\alpha$ " will change and then the core loss cannot be calculated according to the "AC Steinmetz law" ( $\left.P_{t}=k_{a c} B_{m}^{n} f^{\alpha}\right)$. Here, we integrate the variable " $f^{\prime \prime}$ into the coefficient " $k_{t}$ " and the exponent " $N$ " and determine the coefficient " $k_{t}$ " and the exponent " $N$ " of the formula- $P_{t}=k_{t} B_{m}^{N}$ by fitting. Further to find out the dependence of " $k_{t}$ " and " $N$ " on the frequency by fitting. Thereby " $k_{t}$ " and " $N$ " can be obtained in the certain frequency range and the iron loss can be predicted at other frequencies according to the formula- $P_{t}=k_{t} B_{m}^{N}$.

And when designing a core for using at a certain frequency or a certain frequency range, the core loss and magnetic induction intensity are important indicators. Based on some iron losses data and fitting results, designers can calculate iron losses at different frequencies according to the formula- $P_{t}=$ $k_{t} B_{m}^{N}$. The design of magnetic induction intensity is not only related to the composition and structure of the magnetic material, but also to the upper limit of the design of the iron loss. According to the requirements of iron loss, designers can also calculate the design of magnetic induction intensity.

\section{Conclusions}

Magnetic properties of the melt-spun Fe-6.5 wt. \% Si ribbons are investigated before and after heat treatment at $1000^{\circ} \mathrm{C}$. DC properties are greatly improved, as well as the iron loss in the frequency range of $400 \mathrm{~Hz}$ to $10 \mathrm{kHz}$. Above $10 \mathrm{kHz}$, the melt-spun ribbons exhibit a lower total iron loss compared with the annealed one.

A simplified formula based on the Steinmetz law is proposed and verified to predict the AC iron loss for high silicon steel ribbons in the range of $400 \mathrm{~Hz}$ to $5 \mathrm{kHz}$ and the results are presented in this paper according to iron losses data, " $k_{t}$ " and " $N$ " of the simplified formula- $P_{t}=k_{t} B_{m}^{N}$ can be determined, and the AC iron losses can be predicted. The method developed in this work could be used for other magnetic materials to predict AC iron loss with ease.

Acknowledgments: Financial support from the National Natural Science Foundation of China (No. U1660115, 51471031 and 51301019) is gratefully acknowledged.

Author Contributions: All co-authors have contributed substantially to the paper. Shuai Wang conceived, designed, and performed the experiments; Biao Chen contributed to the magnetic properties test; Shuai Wang wrote the manuscript; Yongfeng Liang, Feng Ye, and Junpin Lin supervised the work.

Conflicts of Interest: The authors declare no conflict of interest.

\section{References}

1. Bozorth, R.M. Ferromagnetism; Van Nostrand-Reinhold: New York, NY, USA, 1951; Volume 595, pp. 50-52. ISBN 0-7803-1032-2.

2. Viala, B.; Degauque, J.; Baricco, M.; Ferrara, E.; Pasquale, M.; Fiorillo, F. Magnetic and mechanical properties of rapidly solidified Fe-Si 6.5 wt. \% alloys and their interpretation. J. Magn. Magn. Mater. 1996, 160, 315-317. [CrossRef]

3. Haiji, H.; Okada, K.; Hiratani, T.; Abe, M.; Ninomiya, M. Magnetic properties and workability of $6.5 \% \mathrm{Si}$ steel sheet. J. Magn. Magn. Mater. 1996, 160, 109-114. [CrossRef]

4. Li, H.; Liang, Y.F.; Ye, F. Effect of heat treatment on ordered structures and mechanical properties of Fe-6.5 mass \% Si Alloy. Mater. Trans. 2015, 56, 759-765. [CrossRef]

5. Liu, S.Q.; Cui, C.X.; Wang, X.; Li, N.; Shi, J.J.; Cui, S.; Chen, P. Effect of Cooling Rate on Microstructure and Grain Refining Behavior of In Situ $\mathrm{CeB}_{6} / \mathrm{Al}$ Composite Inoculant in Aluminum. Metals 2017, 7, 204. [CrossRef]

6. Tan, X.; Li, H.Y.; Xu, H.; Han, K.; Li, W.D.; Zhang, F. A Cost-Effective Approach to Optimizing Microstructure and Magnetic Properties in $\mathrm{Ce}_{17} \mathrm{Fe}_{78} \mathrm{~B}_{6}$ Alloys. Materials 2017, 10, 869. [CrossRef] [PubMed]

7. Liang, Y.F.; Wang, S.; Li, H.; Jiang, Y.M.; Ye, F.; Lin, J.P. Fabrication of Fe-6.5 wt. \% Si ribbons by melt spinning method on large scale. Adv. Mater. Sci. Eng. 2015, 2015, 296197. [CrossRef] 
8. Palmer, J.; Thompson, C.V.; Smith, H.I. Grain growth and grain size distributions in thin germanium films. J. Appl. Phys. 1987, 62, 2492-2497. [CrossRef]

9. Steinmetz, C.P. On the law of hysteresis. Proc. IEEE 1984, 72, 197-221. [CrossRef]

10. Kollár, P.; Olekšáková, D.; Vojtek, V.; Füzer, J.; Fáberová, M.; Bureš, R. Steinmetz law for ac magnetized iron-phenolformaldehyde resin soft magnetic composites. J. Magn. Magn. Mater. 2017, 424, 245-250. [CrossRef]

11. Svensson, L.; Frogner, K.; Jeppsson, P.; Cedell, T.; Andersson, M. Soft magnetic moldable composites: Properties and applications. J. Magn. Magn. Mater. 2012, 324, 2717-2722. [CrossRef]

(C) 2018 by the authors. Licensee MDPI, Basel, Switzerland. This article is an open access article distributed under the terms and conditions of the Creative Commons Attribution (CC BY) license (http://creativecommons.org/licenses/by/4.0/). 